\title{
Las autodefensas en Michoacán, México: ¿rescate de la ciudadanía ante la violencia?*
}

\author{
Martha Elisa Nateras González* \\ Recibido: 23 de noviembre de 2016 • Aprobado: 19 de octubre de 2017 \\ https://doi.org/10.22395/ojum.v17n33a6
}

\begin{abstract}
RESUMEN
En la actualidad los sistemas democráticos viven una crisis de representatividad y de confianza, provocando que penetren con fuerza movimientos sociales con un repertorio simbólico lleno de experiencia crítica, que buscan canalizar su descontento social ante un Estado que no les garantiza seguridad. Por ello, la aparición de varios grupos de autodefensa en el estado de Michoacán, a principios de 2013, provocó distintas reacciones en algunos medios de comunicación, los cuales dividieron su juicio respecto a la legitimidad de estos grupos, el tipo de armas que utilizaban y su forma de operar. Por tanto, el objetivo de este artículo es analizar los grupos de autodefensa como un ejercicio de ciudadanía activa y de acción colectiva, al margen de los canales convencionales de participación. El principal hallazgo de este ejercicio analítico-descriptivo es que la participación de la sociedad fuera del control estatal no tiene cabida, aun cuando se presuma que México es un Estado democrático.
\end{abstract}

Palabras clave: Seguridad; autodefensas; ciudadanía; Estado; acción colectiva.

\footnotetext{
Este artículo es el resultado del trabajo de investigación que la autora realiza como integrante del Sistema Nacional de Investigadores, el cual gira en torno a tres grandes temas: ciudadanía, seguridad y violencia en México. Previo a este texto ya se publicó otro con el mismo objeto de investigación, el cual se complementa con este, con el título: "Autodefensas en México: fenómeno mediático y reacción social" (Nateras, 2017).

•* Doctora en Ciencias Sociales en el área de Relaciones de Poder y Cultura Política, por la UAM-Xochimilco. Maestra en Ciencias Sociales. Licenciada en Ciencias Políticas y Administración Pública. Profesora de tiempo completo de la Facultad de Ciencias Políticas y Sociales de la Universidad Autónoma del Estado de México (Uaemex), desde el año 2000. Perfil Prodep, desde noviembre de 2006 y miembro del Sistema Nacional de Investigadores Nivel I, desde enero de 2014. Orcid https://orcid.org/0000-0002-7045-1400. Correo electrónico: marnateras@yahoo.com.mx
} 


\title{
Armed Vigilant Groups in Michoacán, México: Rescue of the Citizen due to Violence?
}

\begin{abstract}
At present, democratic systems are experiencing a crisis of representativeness and trust, causing social movements with a symbolic repertoire full of critical experience to penetrate with force, seeking to channel their social discontent in the face of a State that does not guarantee them security. Thus, the emergence of several vigilant groups in the state of Michoacán in early 2013 provoked different reactions in some media, which divided their judgment on the legitimacy of these groups, the type of weapons they used and their mode of operation. Therefore, the objective of this paper is to analyze armed vigilant groups as an exercise of active citizenship and collective action, outside the conventional channels of participation. The main finding of this analytical-descriptive exercise is that society's participation outside of state control has no place, even when Mexico is assumed to be a democratic state.
\end{abstract}

Keywords: Security; Armed Vigilant Groups; citizens; Government; collective actions.

\section{As autodefesas em Michoacán, no México: resgate da cidadania diante da violência?}

\section{RESUMO}

$\mathrm{Na}$ atualidade, os sistemas democráticos vivem uma crise de representatividade e de confiança, o que desencadeia a forte entrada de movimentos sociais com um repertório simbólico cheio de experiência crítica, que buscam canalizar seu descontentamento social diante de um Estado que não lhes garante segurança. Por isso, o surgimento de vários grupos de autodefesa no estado de Michoacán, no início de 2013, provocou diferentes reações em alguns meios de comunicação, os quais dividiram sua opinião com respeito à legitimidade desses grupos, ao tipo de armas que utilizavam e à sua forma de operar. Portanto, o objetivo deste artigo é analisar os grupos de autodefesa como um exercício de cidadania ativa e de ação coletiva, à margem dos canais convencionais de participação. A principal descoberta desse exercício analítico-descritivo refere-se a que a participação da sociedade fora do controle estatal não tem cabimento, ainda quando se presume que o México é um Estado democrático.

Palavras-chave: Ação coletiva; autodefesas; cidadania; Estado; segurança. 


\section{INTRODUCCIÓN}

El surgimiento de varios grupos, denominados por ellos mismos, como autodefensas, en el estado de Michoacán, como proceso emergente, provoca que broten distintas interpretaciones y lecturas acerca de un nuevo orden social, con nuevos contextos, acontecimientos y situaciones donde los actores sociales van construyendo sentido, sobre todo a lo emergente, otorgando nuevos componentes a viejos temas de la vida social, como la seguridad y la violencia. Para algunos medios de comunicación, estos grupos eran la respuesta de distintos grupos delictivos que se estaban disputando el territorio, pues portaban armas exclusivas de las fuerzas armadas, equipo táctico y operativo, así como de comunicación. Para otros, eran grupos que emergieron debido a la incapacidad del Estado para atender sus demandas y por no poder detener a los grupos delictivos, que desde hace varios años tienen asolada a la población de esta entidad federativa.

Su aparición tuvo cierto grado de legitimidad por dos razones: primero, porque el discurso del modelo de seguridad ciudadana señala tener un enfoque integral y alentar la participación de los diversos sectores sociales en la prevención de la violencia, y segundo, porque en la tradición indígena la participación de la ciudadanía es fundamental en las tareas de seguridad. No obstante, el discurso que predominó es que la responsabilidad de proporcionar seguridad e impartir justicia solo le compete al Estado.
En esta lógica, el sustento de estos grupos, por supuesto, nunca fue jurídico. Su principal argumento tiene que ver más bien con la tradición indígena ancestral que existe en México, de instrumentación de cuadros de vigilancia que emergen de la propia comunidad ${ }^{1}$. Muestra de estas experiencias, que sobreviven desde el siglo XIX, son las guardias tradicionales seris, yaquis y mayos, quienes en defensa de su territorio y sus derechos como pueblo se han enfrentado al Estado, generando mecanismos de autoprotección. Otro ejemplo que ha sobrevivido de la lucha de los mayas contra el colonialismo y la esclavitud es la guardia tradicional maya, en el municipio de Carrillo Puerto, Quintana Roo. Estos modelos son muestra de que la función de seguridad para los pueblos mesoamericanos estaba vinculada a la idea de participación, es decir, la autodefensa; por tanto, la seguridad se convierte en tarea de todos, pues en esta labor se juegan la confianza, la fraternidad y la solidaridad de la sociedad (Nateras, 2017). Se trata de experiencias que se implementaron desde la propia comunidad para atender funciones de seguridad que el Estado no logra o no quiere realizar, en busca del orden y la paz social.

Es por eso que de acuerdo con Villamil (como se citó en Nateras, 2017) este tipo de protección y vigilancia es un modelo

\footnotetext{
Considerando que el referente, para el caso de México, son estas prácticas ancestrales, no se retoman los modelos de autodefensa que han surgido en otros países latinoamericanos, pues se parte del supuesto que esta tradición es la que se rescata para llevar a cabo ese ejercicio ciudadano y de acción colectiva encaminado a la protección de la población michoacana.
} 
ético y moral basado en rituales y pautas de comportamiento de los pueblos indígenas, que se han visto seriamente alterados por una serie de fenómenos como la violencia criminal en entidades como Guerrero, Oaxaca y Michoacán.

A partir de lo anterior, el objetivo de este artículo es analizar a los grupos de autodefensa que surgieron en Michoacán, como un ejercicio de ciudadanía activa, pero también de acción colectiva, debido a que su participación estaba encaminada a intervenir directamente en un asunto que estaba afectando la vida de sus comunidades: la violencia provocada por la delincuencia organizada.

La perspectiva de análisis consiste en mirar a las autodefensas como actores colectivos que consiguieron construir cierto grado de solidaridad e identidad, pero al operar en los márgenes del orden estructural (legal e institucional) no lograron la legitimidad e interacción necesarias para garantizar su permanencia y el cumplimiento de la meta propuesta: proteger a sus comunidades, librándolas de la violencia y la delincuencia. Esta tarea se vio limitada, entre otras cosas, a que eran mal vistos por algunos sectores sociales y políticos, que no estuvieron dispuestos a aceptar que la seguridad pública se atendiera desde la sociedad, aun cuando estos eran una respuesta lógica a la incapacidad del Estado de detener la creciente ola de delincuencia en esa entidad. Asimismo, el tratamiento institucional que se les dio a las denominadas "autodefensas" es la evidencia contundente de que la participación de la sociedad fuera del control estatal no tiene cabida, aun cuando se presuma que México es un Estado democrático.

Para alcanzar el objetivo propuesto el artículo está dividido en cuatro partes. En el primer punto se problematiza en torno a la ciudadanía y la acción colectiva, a partir de referentes teóricos que permitan analizar las razones que motivan la participación ciudadana en el espacio público y en los asuntos públicos, ya sea de manera individual o colectiva, en aras del bien común y en el contexto de una democracia. En el segundo punto se hace una breve revisión de los argumentos a favor o en contra de las autodefensas y de cómo estas constituyen una respuesta a la ineficiencia de las políticas de seguridad por parte del Estado. Los puntos tres y cuatro son meramente descriptivos, pues se hace un recorrido rápido de la evolución del narcotráfico y de la delincuencia organizada en México y Michoacán para entender el surgimiento de las autodefensas y también se hace un recuento de las acciones que llevó a cabo el gobierno mexicano para desarticular a las autodefensas. Al final se desarrollan las conclusiones a las que se llegó en este ejercicio analítico-descriptivo.

\section{LAS AUTODEFENSAS COMO ACCIÓN COLECTIVA $Y$ EJERCICIO CIUDADANO}

La ciudadanía tiene que ver con quiénes participan en la vida de las sociedades; se refiere a la vinculación de los ciudadanos a los colectivos, al reconocimiento de sus derechos y a las posibilidades de participación en la toma de decisiones 
de la comunidad a la que pertenecen. La posibilidad de incidir en la toma de decisiones es fundamental para decidir qué actitudes, comportamientos, compromisos y responsabilidades asumirán frente a los otros.

La participación como presupuesto básico de la democracia ha generado un discurso que reclama una ciudadanía, que más que portadora de derechos y obligaciones, las convierta en práctica, es decir, una ciudadanía activa que participe en la vida de la comunidad y tenga mayor presencia e intervención en los asuntos que las afectan directamente. Esto daría paso a una ciudadanización que va más allá de los derechos, que está vinculada con las obligaciones y, por tanto, con la participación de los individuos en el espacio público, en el espacio que compete a todos los ciudadanos.

En este sentido, la ciudadanización tiene que ver con la disposición de los ciudadanos a organizarse con otras personas y participar en la vida pública, y está relacionada fuertemente con el concepto de ciudadanía activa. Si bien este concepto está asociado a la participación en organizaciones políticas, no siempre el sistema político es el referente principal. De hecho, la llamada ciudadanía activa se vincula menos con la política institucional que con las organizaciones sociales; por ello, debido a que los canales convencionales de participación muestran importantes limitaciones para procesar las demandas e intereses de los diferentes grupos sociales, está más orientada a fortalecer el vínculo social en aras de una mejor calidad de la vida social. En este sentido, se trata de una ciudadanización de la política, es decir, de la recuperación de la política como una actividad propia de los ciudadanos, en donde la construcción de espacios ciudadanos de decisión alternativos y autónomos frente al Estado y de contrapoderes al mismo es fundamental (Nateras, 2012).

La transformación de la política y la desconfianza en sus instituciones han provocado que en la actualidad la ciudadanía se exprese en otras esferas, que no son exclusivamente la política y que, además, estas formas de participación ganen fuerza. No obstante, estos tipos de participación política tienden a ser desconocidos por la autoridad formal, ya que tradicionalmente el espacio clásico de la ciudadanía es la "polis" territorial, espacio en el cual se reconocen los derechos del sujeto frente al poder. Este es un punto fundamental para entender por qué el gobierno federal tomó la decisión de disolver las autodefensas.

En la actualidad las movilizaciones como forma de participación, pero también como forma de intervención sobre los asuntos públicos, tienen que ver más con cuestiones sociales que con políticas. La participación en el espacio público, ya sea en el ámbito político o en el social, no puede ser considerada exclusivamente como un fenómeno colectivo, pero tampoco debe reducirse a un comportamiento estrictamente individual; más bien ubica el comportamiento del individuo en interrelación con su entorno, es decir, a partir de su habitus -en el sentido de 
Bordieu-como el principio generador de las prácticas sociales.

Las actividades sociales se reproducen en la vida cotidiana, tanto al nivel individual como al colectivo; a partir de ellas cada individuo se proyecta ante los demás, interactúa y adquiere una posición determinada en el funcionamiento y entramado social. El ejercicio de la ciudadanía implica, entre otras cosas, el redescubrimiento de lo político, el fomento del asociacionismo civil, el incremento de la conciencia ciudadana, la construcción de valores colectivos, y el fortalecimiento de las instituciones a través de la confianza de la población. Es ver la ciudadanía en relación con el espacio en el cual ejerce la sociedad civil, es decir, hacer de las organizaciones sociales y de sus acciones el ambiente en el cual se vivencien y se resuelvan los conflictos sociales (Nateras, 2012).

Larry Diamond (1997) concibe a la sociedad civil como el espacio de la vida social organizada auto instituida voluntariamente, independiente, autónoma del Estado y limitada por un conjunto de reglas compartidas. La sociedad civil es una entidad intermediaria entre la esfera privada y el Estado, los actores en la sociedad civil necesitan la protección de un orden legal institucionalizado para preservar su autonomía y libertad de acción. De esta manera, la sociedad civil no solo restringe el poder del Estado sino que legitima la autoridad estatal cuando esta se basa en las reglas de la ley. La sociedad civil comprende un amplio conjunto de organizaciones, formales e informales; es distinta de la sociedad en general, en la medida que involucra a ciudadanos actuando colectivamente en una esfera pública para expresar sus intereses, ideas, intercambiar información, alcanzar objetivos comunes, realizar demandas al Estado, entre otras acciones.

Para Cohen y Arato (2001) la sociedad civil es un espacio de legitimidad democrática, de derechos y de igualdad ante la ley, formada por tres esferas políticamente relevantes: una privada, una pública y otra social, en las que los individuos se reúnen, se asocian y hablan sobre asuntos de interés público, con la intención de influir en la toma de decisiones y, por supuesto, en la sociedad política. En tanto espacio democrático, la participación equitativa de todos los interesados en la discusión pública es fundamental como principio básico de la democracia.

Sin embargo, la organización de la sociedad civil no es un asunto sencillo y la mayoría de las veces es necesario que alguien tome la iniciativa para generar trabajo conjunto. Según Paramio (2005), aunque un número determinado de individuos compartan los mismos intereses, eso no significa que deban actuar conjuntamente en función de esos intereses, pero si todos ellos asumen que el beneficio es mayor a través de la acción colectiva, es factible que planteen organizarse para lograr esos objetivos compartidos.

Para que se detone esta acción colectiva el grado de compromiso de la comunidad y la identidad son fundamentales. Pero, la construcción de la identidad es un proce- 
so muy complejo, que se elabora en los ámbitos social, del género, profesional, sexual, entre otros, a partir de identificaciones. La identidad de las personas no es algo que se defina en un momento concreto, es algo que se cimienta desde el pasado y se va forjando en el tiempo, a través de narraciones y elementos simbólicos que van expandiéndose, construyendo una cultura particular; esto es lo que le da significado y sentido a la vida (Nateras, 2012).

La consolidación de la identidad colectiva es prioritaria sobre cualquier estrategia racional; al reforzar la identidad colectiva es más sencillo desarrollar estrategias cooperativas por parte de todos los miembros del colectivo. Y hasta cierto punto una identidad colectiva fuerte genera una especie de contrato, que se fortalece aún más cuando uno de los integrantes del colectivo tiene la claridad de que no puede abandonar al grupo, porque el precio por salir de él es muy alto (Paramio, 2005).

Para Garretón (2002) el paradigma clásico, teórico y práctico, en relación con los actores sociales y con la acción colectiva que privilegiaba la dimensión estructural se ha transformado radicalmente; por ello propone un esquema de acción colectiva que descansa en tres elementos importantes: Estado; régimen y partidos políticos, y sociedad civil, debido a que históricamente han tenido una relación acotada y definida. A partir de esta nueva configuración se constituye la matriz sociopolítica. En este sentido, la concepción de acción colectiva del autor se refiere más a procesos de lucha y cambio social, y es aquí donde los movimientos sociales, entendidos como acciones colectivas, cumplen con los requisitos de la estabilidad en el tiempo, y cierto grado de organización y de orientación al cambio social.

Así, la idea de movimiento social se mueve en dos sentidos: a) cuando se presenta como respuesta a un determinado momento coyuntural, situación o problema, y b) la encarnación del sentido de la historia y el cambio social. Las teorías de los movimientos sociales se han visto en la necesidad de explicar la relación entre estructura, sujetos y acción, y en esta necesidad han construido un campo de investigación en torno a la movilización social (Retamozo, 2009).

En conclusión, Garretón (2002) afirma que la acción colectiva en contextos autoritarios se funda en dos razones: la autodefensa y la sobrevivencia. En el caso de Michoacán la acción colectiva de las autodefensas se presenta como una lucha basada en la capacidad de realizar acciones de legitimación social con el objetivo de generar cambios en el universo simbólico, pero sobre todo, para el cambio social y en contra de la violencia.

\section{LAS AUTODEFENSAS COMO RESPUESTA A LA INEFICIENCIA DE LAS POLIITICAS DE SEGURIDAD}

Como se refiere en la introducción, desde hace más de una década, la seguridad ciudadana se ha convertido en un asunto primordial en la agenda de los gobiernos de las naciones de América Latina. El dis - 
curso de la seguridad ciudadana ubica a la ciudadanía en el centro de las políticas de seguridad y la involucra activamente, al volverla corresponsable en el diseño, instrumentación y evaluación de la políticas de seguridad. Por tanto, la participación de la ciudadanía es fundamental en el fortalecimiento de la institución policial.

La seguridad ciudadana, hoy establecida como el rumbo discursivo en materia de seguridad, dice tener un enfoque integral que alienta la participación de los diversos sectores sociales en la prevención comunitaria o vecinal, pues en este modelo la corresponsabilidad de la sociedad en las tareas de seguridad y control de la violencia social es fundamental. No obstante, las políticas de seguridad para atender la violencia y la delincuencia han sido poco eficaces; muestra de ello es el surgimiento las denominadas prácticas de "autodefensa", pues estas son la evidencia contundente de que algo no está marchando bien en materia de política de seguridad.

Para algunas voces, estos grupos de autodefensa o autodenominados "policías comunitarias" tenían muy poco o nada de policías, debido a que portaban armas exclusivas del ejército y equipo de radiocomunicación de alta tecnología, lo que hacía suponer que tenían relación con algún grupo delictivo y se decía que realmente la sociedad estaba frente a la creación de ejércitos irregulares al servicio del crimen organizado (Beltrán, 2013). Para otras voces, los ciudadanos; cansados de ser víctimas de la delincuencia, decidieron organizarse para hacer frente a estos problemas y resguardar la integridad de sus comunidades ante la ineficacia de las corporaciones policiacas.

Al respecto nunca hubo un consenso, pero en lo que se puede estar seguro es que los grupos de autodefensa exhibieron la incapacidad del Estado para cumplir con su obligación de salvaguardad la vida y propiedades de los ciudadanos; por ello es que se cuestionaban la función del Estado en materia de seguridad y de impartición de justicia en México. Por tanto, la creación de estos grupos tiene su explicación en la indolencia del Estado con su deber de garantizar la seguridad pública, pero, sobre todo, en el olvido que este ha dejado a ciertos sectores de la sociedad. Por ello, para distintos expertos, su aparición es resultado de un Estado que dejó de proteger la vida y la seguridad de las personas.

Para Escalante (2009) la crisis de seguridad que se está viviendo en México tiene como referente concreto la violencia del crimen organizado, que se materializa en el interior de una sociedad inestable, marcada por la desigualdad, con un sistema político fragmentado y un poder Ejecutivo federal débil -la referencia es al gobierno de Felipe Calderón-. Lo interesante es que, a pesar de que hoy en día no se tiene un Ejecutivo federal débil, el actual gobierno de Peña Nieto continúo con la estrategia que instrumentó Felipe Calderón, la cual provocó, como bien señala Escalante, que aumentara la tensión en el sistema de relaciones sociales y se multiplicara el conflicto. 
En este sentido, es importante tomar en cuenta que en América Latina una parte importante de los países que la integran pasaron por regímenes autoritarios y por tanto se privilegian las soluciones de tolerancia cero y mano dura; esto implica que el ejercicio de la violencia está legitimado. Es decir, el paradigma autoritario se halla dentro del código genético (Carrillo, 2007). Por eso como dice Carrillo (2007) no deja de ser paradójico que los "regímenes democráticos" de América Latina, por diferentes vías traten de atemperar los efectos de la violencia que provoca la exclusión y la falta de respeto a los derechos humanos.

Por tanto, la pregunta a responder es ¿Cómo comprender y situar los sentidos, atributos y dimensiones de la acción social y política más allá del Estado como cauce exclusivo del discurso y del cambio social?

Por ello, a pesar de que el Estado retoma el modelo de policía de proximidad o de orientación comunitaria para atender el problema de la violencia y la delincuencia no reconoce la legitimidad de las llamadas autodefensas, aun cuando estas argumentaban que su organización estaba orientada a la defensa de la vida ante la ineficiencia de las políticas de seguridad por parte del Estado. Ello demuestra que con el surgimiento de las autodefensas no solo se puso de manifiesto, una vez más, la existencia del crimen organizado en México, sino también la estrecha colaboración que algunas autoridades políticas y policiales mantenían con los delincuentes.

\section{GÉNESIS Y AVANCE DE LAS AUTODEFENSAS EN MICHOACÁN}

El origen de las autodefensas solo se puede entender si se hace una revisión de cómo evolucionó el problema del narcotráfico y de la delincuencia organizada en México.

Dice Rivera (2014) que desde 1940 hasta principios de la década de 1980 el negocio de las drogas ilegales en México se consolidó al expandirse poco a poco por el país, gracias a la demanda del mercado norteamericano; este crecimiento no estuvo mediado por grandes dosis de violencia. Lo anterior se explica por la tolerancia y protección de las autoridades locales y federales mexicanas y esto, como señala Escalante (2009), responde a la organización del sistema priista.

Entre 1950 y 1970 los grupos que se dedicaban al contrabando y a la venta de enervantes estaban diseminados, no existía un poder central que controlara la dinámica de esta actividad ilícita y tampoco había alguna organización visible que estuviera por encima de las demás. Es hasta la década de 1970 cuando nace el cártel de Guadalajara comandado por Miguel Ángel Félix Gallardo, consolidándose como la más fuerte organización de tráfico de drogas en el país en ese momento. Paralelamente en el noreste mexicano se gesta el cártel del Golfo dirigido por Juan Nepomuceno Guerra - de quien se decía que era tío de Juan García Ábrego- (Ravelo, 2011). 
A principios de 1980 Juan García Ábrego se convirtió en el líder del cártel del Golfo; este personaje entró en contacto con los cárteles colombianos, pues esto le permitió consolidarse y convertirse en el eje de casi todos los movimientos de cocaína que pasaban por México (Ravelo, 2011). En las dos décadas siguientes, se fortaleció el poder armado y financiero del crimen organizado de México, incrementándose con ello su capacidad de corrupción y cooptación de ciertas instituciones estatales (Rivera, 2012). En 1996 es detenido y extraditado García Ábrego, heredando la plaza a Osiel Cárdenas Guillen, un ex policía judicial del estado de Tamaulipas, quien cooptó a tropas de élite del Ejército mexicano como brazo armado del cártel. Este fue el inicio de los Zetas ${ }^{2}$, quienes se pusieron al servicio de distintos grupos de narcotraficantes (Ravelo, 2011).

El caso de Michoacán ${ }^{3}$ está vinculado con la historia anterior, es decir, los primeros grupos delincuenciales que se instalaron en esta región provenían del cártel del Golfo y de los Zetas, aunque la historia es más antigua, pues según Rivera (2014) desde la década de 1940 se empezó a cultivar marihuana en el estado de Michoacán y posteriormente amapola para pro-

2 El nombre lo obtienen del lenguaje policíaco de la extinta Policía Judicial Federal (PJF); en el alfabeto fonético, "Z" equivale a jefe de grupo (Ravelo, 2011).

3 Michoacán es un estado localizado al suroeste de México, se caracteriza por tener un excelente clima, extensas serranías mal comunicadas y una población rural pobre, principalmente de la región conocida como Tierra Caliente y de la Sierra Madre del Sur, esto lo hace propicio para que la siembra de marihuana y amapola se convierta en una opción económica más atractiva que los cultivos tradicionales de subsistencia (Rivera, 2014). veer a los exportadores de Sinaloa. Esta actividad creció al amparo de los códigos rancheros de la región, que permitieron armar una red de silencio y solidaridad entre los traficantes y los encargados de sembrarla, para burlar la ley entre ciudades medias y territorios serranos. La década de 1970 es crucial, pues en este período se empieza a cultivar la semilla de marihuana en esta zona, expandiéndose cada vez más. Su situación geográfica ha sido favorable para cultivar droga entre la serranía y la planicie, permitiendo que muchas localidades se convirtieran en narco-pueblos, sobre todo en la franja conocida como el valle de Apatzingán, la cual bordea la Sierra Madre del Sur ${ }^{4}$ (Maldonado, 2012) (ver gráfico n. ${ }^{\circ} 1$ ).

Algunos puntos fronterizos de la región de la Sierra Madre del Sur, que se extiende a los estados de Jalisco, Michoacán y Guerrero, son zonas sin seguridad; esto ha sido favorable para los plantíos de droga y lo accidentado del lugar obligó a construir pistas aéreas para el tráfico de drogas (Maldonado, 2012) (ver gráfico n. 1 ).

Desde que inicia el cultivo y tráfico de marihuana hasta principios del siglo XXI esta actividad se desarrolló de manera "pacífica". Sin embargo, a partir de 2002 o 2003, los michoacanos empezaron a dejar de ver al narcotráfico como un fenómeno cercano, pero "inofensivo", para empezarlo a asociar a la delincuencia organizada, la cual generaba además de

Los municipios más representativos de esta región son: Tepalcatepec, Buenavista, Apatzingán, Arteaga y Aguililla (Maldonado, 2012). 
Figura 1. Ubicación de Michoacán y municipios con presencia de autodefensas

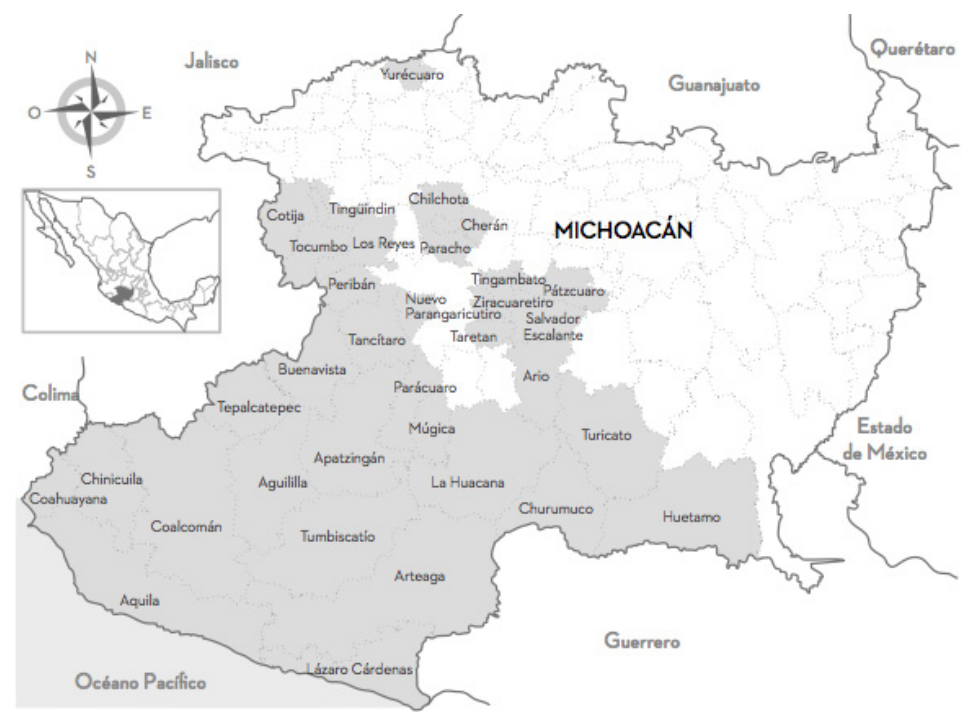

Fuente: Valdivia, 2014, p. 187

tiroteos, amenazas, pago forzado de cuotas, secuestros y ejecuciones de víctimas (Rivera, 2014) .

Como se indica en líneas anteriores, los Zetas en 2006 dan origen a la Familia Michoacana, un grupo formado por ex aliados y discípulos de este grupo delincuencial; desde su aparición anuncian que su propósito era liberar a Michoacán de los Zetas. Su primer acto público fue lanzar a la pista de baile de una discoteca cinco cabezas humanas y una cartulina con un mensaje $\mathrm{e}^{5}$ en la ciudad de Uruapan (municipio de Michoacán), en septiembre de 2006. Durante los días subsecuentes varios periódicos locales publicaron el manifiesto de la Familia Michoacana, en el cual se autodefinía como una organi-

5 El mensaje decía: "La Familia no mata por paga. No mata mujeres, no mata inocentes, solo muere quien debe morir, sépanlo toda la gente. Esto es justicia divina" (Rivera, 2014, p. 6). zación integrada por trabajadores de la región de Tierra Caliente, organizados por la necesidad de terminar con la opresión y la humillación de la gente que siempre ha detentado el poder; en el citado manifiesto señalan entre sus objetivos el de imponer el orden, terminar con el secuestro, la extorsión, los robos y los asesinatos, así como con la venta local de drogas sintéticas (Rivera, 2014).

Este manifiesto es una mezcla de discurso religioso, moral y de radicalismo social, que intenta justificar sus acciones delictivas y lograr simpatía y apoyo popular ${ }^{6}$. Lo cierto es que la Familia Michoacana sí logró hacerse de una base social de

6 El vocero y principal propagandista de la Familia era Servando Gómez Martínez "la Tuta", un profesor rural formado en las filas del radicalismo de izquierda del sindicato magisterial, contribuyó a atraer simpatías con su discurso antigubernamental, populista y justiciera (Rivera, 2014). 
apoyo, no solo porque ofrece a la población liberarla de las extorsiones, robos y violencia de los Zetas, sino porque, además, sus operadores proporcionaban recompensas a quienes les ayudaban con información o servían como intermediarios para impulsar su negocio; asimismo, porque su oferta de "protección" iba acompañada de amenazas que no se podían ni debían minimizar (Rivera, 2014).

Cabe señalar que la Familia Michoacana cuando surgió declaró como su objetivo fundamental cuidar a los michoacanos de cualquier grupo que pretendiera entrar en Michoacán a imponer sus leyes; para desacreditar a los otros grupos utilizaba "narco mensajes" dirigidos a sus rivales, a los cuerpos policiales, al gobierno federal y a todo aquel que se interpusiera en sus planes y negocios (Maldonado, 2013).

El dominio y el statu quo impuesto por este grupo delictivo se mantuvo hasta 2010, pero después de una serie de disputas internas acompañado de una secuela de ejecuciones, en marzo de 2011 se anunció el surgimiento de una nueva organización denominada los Caballeros Templarios ${ }^{7}$. El nombre de Caballeros Templarios lo

7 A finales del 2010 circula la noticia de que fue abatido Nazario Moreno, "el Chayo", el principal fundador y pionero del cártel de "la Familia Michoacana". Esa supuesta muerte, junto con la detención de José de Jesús "el Chango" Méndez, el 21 de junio del 2011, fracturaron al grupo, hasta que Servando Gómez Martínez, "la Tuta", se separó del grupo y se llevó consigo a Enrique "Kike" Plancarte, con el que fundó la nueva organización de "los Caballeros Templarios", que anunció públicamente su aparición en marzo de 2011, reproduciendo las mismas tácticas y estrategias de penetración política y social de la Familia Michoacana (Carrasco y Castellanos, 2012). adoptó Nazario Moreno alias "el Chayo", quien creó un "código michoacano" inspirado en la regla templaria. Al igual que la Familia Michoacana, difundieron su "código de conducta", casi religioso, a través de folletos en los que justifican su existencia, afirmando su lucha contra la pobreza, la tiranía y la injusticia e invocaban al corazón y a la mente de las personas para salvar al pueblo (Sánchez, 2013).

La aparición pública de los Caballeros Templarios fue igual de espectacular que la de la Familia Michoacana, cuando en junio de 2011 colgaron los cuerpos de dos jóvenes de unos puentes peatonales en Tierra Caliente. Entre la segunda y tercera semanas de junio, de ese año, la pugna entre ambas agrupaciones se agudizó, el resultado de ésta fue la muerte de alrededor de 40 personas. Asimismo, iniciaron las amenazas contra los funcionarios públicos, provocando la renuncia de distintas autoridades, dejando los poderes públicos acéfalos (Maldonado, 2012).

El dominio de los Caballeros Templarios se extiende por todas las regiones de Michoacán, y para mantener el sello de la casa, anunciaron que continuarían con las actividades "altruistas" que antes realizaba la Familia Michoacana. De hecho, tardaron poco en recuperarse de la escisión y detentar de nueva cuenta el monopolio del tráfico de drogas y las extorsiones; pero, además, ampliaron su imperio, con la exportación ilegal de mineral de hierro rumbo a China, el contrabando de efedrinas y toda clase de mercancías ilícitas.

\footnotetext{
Se dice que este personaje perteneció al cártel del Golfo
} 
Como ya se había señalado, esta expansión no se puede entender sin la complacencia y la complicidad de autoridades de los tres niveles de gobierno (Rivera, 2014). Por tanto, la Familia Michoacana y los Caballeros Templarios terminaron por convertirse en irreconciliables enemigos a muerte, confrontación que provocó innumerables muertos, entre ellos decenas de decapitados y una disputa por el liderazgo y el control del negocio.

Como bien señala Jaime Rivera (2014) la Familia Michoacana y los Caballeros Templarios pudieron asentarse y prosperar gracias a la virtual ausencia del poder del Estado o, inclusive, a la ayuda de algunas instancias oficiales. En poblados rurales de la Tierra Caliente o la Sierra del Sur, el poder estatal siempre ha estado distante, la aplicación de la ley es opcional y los gobiernos municipales son débiles. El gobierno del estado de Michoacán, con más recursos que los ayuntamientos y facultado para prevenir y perseguir los delitos, fue particularmente omiso durante el período de la lucha entre los cárteles. En unos cuantos años, la Familia y los Templarios lograron tejer una extensa red de control sobre las corporaciones policiacas y gobiernos municipales, a los que extorsionaban, sometían y ponían a su servicio (Rivera, 2014).

Lo cierto es que, como dice Maldonado (2013), la fuerza de estos grupos no es tan arbitraria como se piensa o que llegan a imponer su voluntad; en realidad su poder hay que entenderlo con cierta aceptación o tolerancia, resistencia o negociación de los grupos de poder de la localidad. Esta es la manera en que se negocia la violencia y se construyen ciertas legitimidades del orden ilegal.

Como ya se dijo, el respaldo social que llegaron a tener estas organizaciones en algunas localidades y entre ciertos grupos organizados, así como el uso de las armas para amenazar y castigar, el dinero para corromper y compensar a los informantes fueron factores decisivos para someter a poblaciones enteras. Para construir su imperio del miedo, dice Rivera (2014) que llevaron a cabo actos de violencia: homicidios, incendios, secuestros, exhibición macabra de cadáveres, sin recibir castigo alguno; asimismo recurrieron a las amenazas creíbles y castigo a quienes se resistieran; y por último lograron que ninguna autoridad diera protección a las víctimas. Con este entramado criminal, la reproducción del miedo era automática; por tanto, el dominio de un pequeño grupo de sicarios a un número considerable de personas era un asunto fácil (Rivera, 2014).

A partir de estos planteamientos y de lo que comenta Basave se puede entender la participación o contemplación de la sociedad, pues "la entronización del crimen organizado en pueblos y ciudades, ejerciendo atribuciones de recaudación fiscal, de patrullaje y seguridad, de administración e impartición de justicia, de financiamiento de obras públicas y generación de empleos provoca el envilecimiento del tejido social" (2010, p. 89).

Si a lo anterior se le suma la escasa capacidad de respuesta del Estado para 
prevenir y combatir la violencia, así como su debilidad para generar seguridad, entonces se puede concluir que la seguridad es un bien público cada vez más preciado y escaso (Carrillo, 2007). Por tanto, al ser un bien público escaso, dicen Arriagada y Godoy (2000) el acceso a la seguridad no es igual para todas las personas, siendo los sectores más empobrecidos los que menos tienen acceso a ella, mientras que los grupos más prósperos gozan de toda la gama de servicios ofrecida por los cuerpos policiales.

Justo este último punto es el que permite que tanto la Familia Michoacana como los Caballeros Templarios articulen un discurso de protección a los pueblos y que incluso logren el apoyo popular, ya que muchas poblaciones no contaban con la protección de los distintos cuerpos de seguridad. Pero la realidad era que los Caballeros Templarios tenían sometida a la población de esta entidad, cobrándole impuestos por negocios, tierras y consumo de alimentos, extorsionándola por sus posesiones como casas, autos y cobrándose hasta con sus mujeres. Retomando a Fuentes (2014) la diversificación de las actividades de los distintos grupos delincuenciales ha generado un verdadero despotismo tributario, el cual está mediado por el posicionamiento de su control territorial y acompañado por el establecimiento de un orden paralegal que está en constante disputa con la soberanía estatal. Por tanto, este nuevo "orden" que se caracteriza por el abuso de poder, tarde o temprano, dañaría a la población supuestamente protegida; los ejemplos de esto son los casos de violación de las hijas de familia y de las esposas de aquellos para-contribuyentes.

Esta breve historia, en la que cada vez empiezan a ser más visibles los excesos y los constantes abusos, provocó que en febrero de 2013 surgieran, públicamente, los primeros grupos de autodefensas en dos municipios de Tierra Caliente, Michoacán: Buenavista Tomatlán y Tepalcatepec, colectivos que desde un principio se mostraron dispuestos a enfrentarse a los Caballeros Templarios y detener el latrocinio del que eran víctimas miles de pobladores. El argumento para justificar su irrupción al espacio público y legitimar sus funciones como guardianes del orden y de la paz social era que ya estaban cansados de los crímenes y abusos de los Templarios y de la inacción o complicidad de los gobiernos, que por ello recurrían a las armas en defensa propia. A las autodefensas se integraron comerciantes, productores de limón y aguacate, ganaderos, empresarios agrícolas profesionistas de la zona, entre otros, y al frente a esta red de autodefensas estaba el médico y profesor José Manuel Mireles Valverde?.

Posteriormente, surgen los grupos de Coalcomán, Aguililla y Chinicuila, en la Sierra del Sur; en la región de la Costa: los de Aquila y Coahuayana y en la parte norte del estado, en Yurécuaro (ver gráfico n. ${ }^{\circ} 1$ y n. ${ }^{\circ} 2$ ). La expectativa del Consejo de Autodefensas, según señalaban en noviembre de 2013 era la de expandirse a muchos municipios más (Rivera, 2014).

Líder del grupo de autodefensa de Tepalcatepec. 
En su primer año los grupos de autodefensa, encabezados por José Manuel Mireles, se mantuvieron unidos y liberaron de los Caballeros Templarios a 28 municipios (ver gráfico n.․ 2); durante ese tiempo, las autodefensas tuvieron índices de popularidad y legitimidad muy altos; la ciudadanía confiaba en que ellos lograran restablecer la seguridad pública y combatir al crimen organizado, tarea que no había logrado Felipe Calderón y que tampoco estaba atendiendo Peña Nieto (Olmos, 2014).

Sin embargo, como se verá en el siguiente punto, su poder terminará por ser eclipsado, pues lo que se estaba disputando con sus acciones no era solo la defensa de la sociedad, sino la soberanía estatal.

\section{LA INSTITUCIONALIZACIÓN DE LAS AUTODEFENSAS COMO RESPUESTA DE LA CIUDADANIZACIÓN DE LA SEGURIDAD}

La concepción hobbesiana en torno a la creación del Estado con una función fundamental: la de garantizar la seguridad de las personas, y por otro lado, la concepción weberiana que establece que solo el Estado ostenta el uso de la violencia legítima son dos discursos a los que recurre el gobierno federal para impugnar la existencia de las autodefensas, pero también hace una fuerte crítica a sus prácticas de combate. Los argumentos para deslegitimar a los grupos de autodefensa fueron varios, entre los que destacan: que se autodenominaban "comunitarias", que violaban flagrantemente la ley de armas

Figura 2. Regiones y municipios de Michoacán con presencia de grupos de autodefensa, 2014

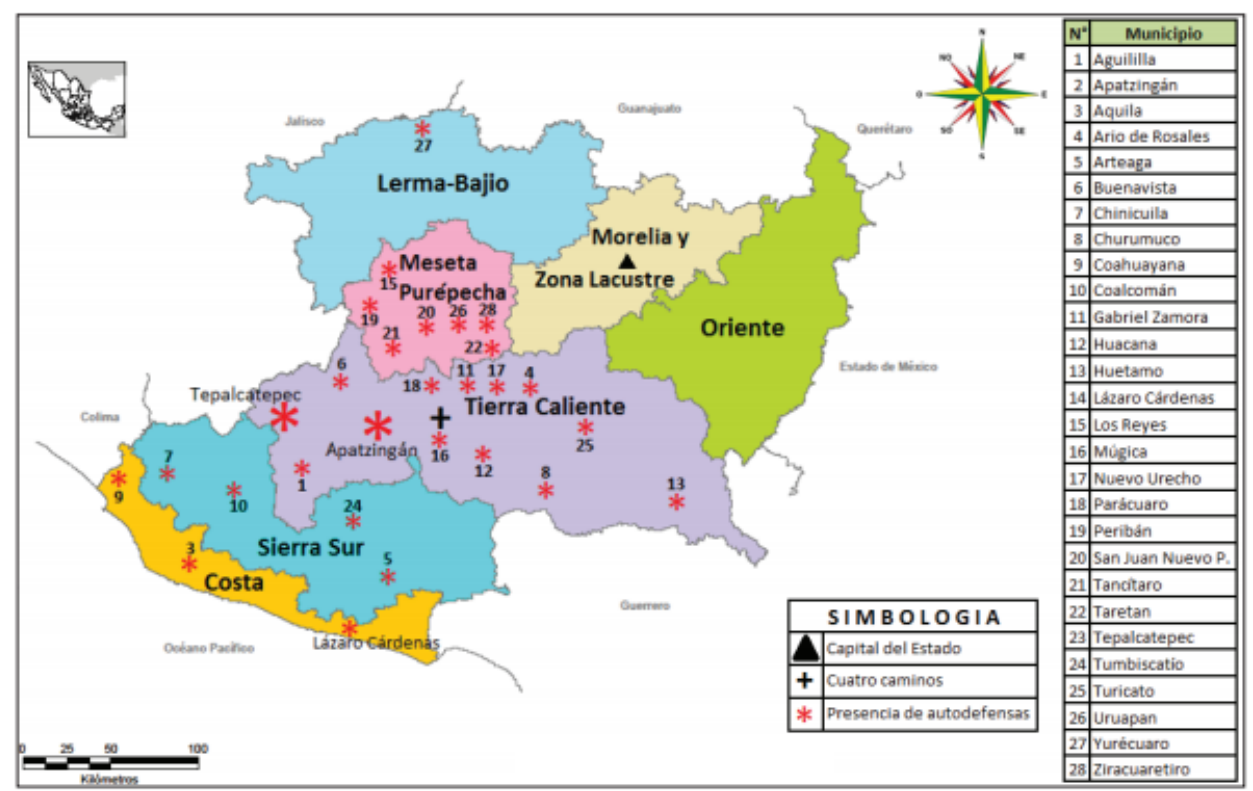

Fuente: Rivera, 2014, p. 12 
y explosivos, usurpaban funciones de la policía y recurrían a la violencia para intimidar a personas pacíficas.

Estos argumentos, vertidos o reproducidos por distintos medios de comunicación, provocaron que el gobierno federal tomara las riendas de este conflicto y habilitara a un actor para hacerse cargo de esta situación; este personaje fue Alfredo Castillo Cervantes, con el cargo de Comisionado para la Seguridad y el Desarrollo Integral de Michoacán. Cabe señalar, que antes de la incorporación de este representante del gobierno federal, esta instancia de gobierno solo se había mostrado como un observador neutral, que contemplaba desde afuera el acelerado proceso de descomposición en Michoacán. Pero a partir de su inclusión como actor central inició una serie de acciones que, más que estar orientadas al combate de la delincuencia organizada, empiezan a articular un discurso en torno a la necesidad de regularizar a los grupos de autodefensa. Para tal fin los gobiernos federal y estatal firmaron un acuerdo de ocho puntos con grupos de ciudadanos de la entidad, para integrarlos a la vida institucional ${ }^{10}$. El documento esta-

10 Los principales puntos de este acuerdo son los siguientes:

Las autodefensas se institucionalizan al incorporarse a los Cuerpos de Defensa Rurales. Para este fin, los líderes de las autodefensas presentaron una lista con todos los nombres de sus integrantes, los cuales serían validados con la formación del expediente respectivo, controlado por la Secretaría de la Defensa Nacional. Estos cuerpos serían temporales y estarían bajo el mando de la autoridad en los términos de las disposiciones aplicables.

Para la protección de sus comunidades, personal de las autodefensas formarían parte de la blecía que su propósito era recomponer la tranquilidad y el orden públicos con un enfoque integral, considerando aspectos sociales, económicos y culturales; por tanto, para logar este cometido, utilizaría los instrumentos legales necesarios para crear un ambiente de institucionalidad duradero y estable.

La alianza entre los gobiernos federal y estatal se materializa en enero de 2014 cuando Fausto Vallejo, gobernador de Michoacán en turno, y el comisionado federal, Alfredo Castillo, acordaron la "institucionalización" de los grupos de autodefensa. Para reafirmar su poder como autoridad central, el comisionado Castillo llevó a cabo una serie de acciones de corte autoritario: comienza por negociar con distintos líderes de las autodefensas y en marzo estableció un plazo para su desarme, así como su disolución; removió al Secretario de Seguridad Pública, al Procurador de Justicia y al Secretario Ejecutivo del Consejo Estatal de Seguridad y designó en su lugar a hombres de su confianza, designación que por ley corresponde al gobernador del Estado; esto constituye una muestra inobjetable de que el Presidente de la República le estaba otorgando poderes absolutos ${ }^{11}$. Ante esas decisiones

Policía Municipal siempre y cuando acreditaran los requisitos de ley y contaran con el aval del Cabildo de su Ayuntamiento para ser propuesto para formar parte de dicha policía.

Las autodefensas quedan obligadas a registrar las armas que posean o portan ante la Secretaría de la Defensa Nacional.

Información retomada de la siguiente página de internet: (https://www.animalpolitico.com/2014/01/ las-autodefensas-seran-legales-conoce-los-8-puntos-que-acordaron-con-el-gobierno/).

"Según un informe de la Comisión Nacional de Se- 
se enfrentó a la resistencia de algunos líderes como Hipólito Mora ${ }^{12}$ o José Manuel Mireles, pero también contó con el apoyo de otros como Estanislao Beltrán, alias Papá Pitufo, quien se incorporó a la Fuerza Rural en la zona de Tierra Caliente, corporación que se crea en sustitución de la policía municipal; este último personaje fue pieza clave para la institucionalización de estos grupos (Rivera, 2014).

Papá Pitufo al darle la espalada a José Manuel Mireles, provocó su destitución al frente del Consejo General de Autodefensas, remoción avalada y apoyada por las autoridades federales y estatales, autoridades que habían sido señaladas previamente por Mireles de tener nexos con la delincuencia organizada ${ }^{13}$.

La colaboración -subordinación- del gobierno del estado de Michoacán en este proceso es fundamental; ejemplo de ello es la petición que Jesús Reyna García ${ }^{14}$,

guridad del 14 de enero hasta el 27 de febrero de 2014 se detuvieron a 675 presuntos delincuente, se liberó a 10 víctimas de secuestro, se decomisaron 418 kilos de marihuana y 61 de droga sintética así como 255 armas ligeras, 30 granadas y un lanzacohetes (Olmos, 2014).

12 Líder del grupo de autodefensa de la comunidad la Ruana.

13 En una entrevista, el mes de julio de 2013, José Manuel Mireles, afirmó que el gobernador interino, Jesús Reyna, pertenecía al cártel de los Caballeros Templarios, asimismo, señala la pertenencia al crimen organizado de muchos de los Presidentes Municipales, de los cuerpos de la Policía Municipal, de los cuerpos de la Policía Estatal y los Ministerios Públicos. Información retomada de la siguiente página de internet: (https://www.proceso. com.mx/348801/ligan-a-gobernador-interino-demichoacan-con-los-templarios).

14 Quedó como encargado del Ejecutivo local, tras el retiro temporal del gobernador Fausto Vallejo
Secretario de Gobierno y encargado de la gubernatura de Michoacán, hizo a los grupos de autodefensa para regularizarse y reencauzar sus actividades dentro de la legalidad, porque desde su perspectiva estaban violando deliberadamente la ley. Esto permitió que el comisionado federal iniciara el proceso de desarme de los grupos de autodefensas de manera paulatina. Una de las condiciones que las autodefensas exigieron para iniciar el desarme era la detención de los principales líderes de los Caballeros Templarios, condición que no se cumplió del todo.

A pesar de las medidas autoritarias, anteriormente señaladas, por parte del comisionado Castillo, el gobierno federal no utilizó la fuerza física para desarmar a las autodefensas, por eso les ofreció una opción intermedia: disolverse como grupos independientes y convertirse en Cuerpos de Defensa Rurales, pero actuando en el marco de la ley y subordinados a un mando institucional (Rivera, 2014).

Lo que siempre mostró el comisionado para la Seguridad y el Desarrollo Integral de Michoacán fue una gran desconfianza hacia los órganos de seguridad del estado. Porque, como señala Basave (2010), "nadie sabe dónde termina la delincuencia y dónde empieza la justicia" (p. 90). Por ello se dio a la tarea de identificar y desbaratar la protección que recibían los delincuentes de las distintas instancias del gobierno estatal, pero al mismo tiem-

Figueroa, pero a finales de mayo de 2014 un juez federal dictó auto de formal prisión en su contra, por el delito de delincuencia organizada y posibles nexos con los Caballeros Templarios. 
po llevó a cabo acciones para dividir a los líderes de las autodefensas y se empezó a reunir con personajes que no se tenía claridad a qué bando pertenecían. "Pues paralelamente al combate frontal se dan negociaciones y pactos... encuentros clandestinos entre autoridades y criminales donde se sellan acuerdos de tolerancia a cambio de paz, valores entendidos que ambas partes cumplirán al margen de la ley" (Basave, 2010, p. 90).

A la par del proceso de institucionalización de las autodefensas y la instrumentación de una estrategia ofensiva en contra de estas, empiezan a caer distintos capos y funcionarios vinculados con los Caballeros Templarios. Primero fue detenido Dionicio Loya Plancarte "el Tío", uno de los líderes de este grupo delictivo; después fue abatido Francisco Galeana Núñez "el Pantera", extorsionador de los Caballeros Templarios. Posteriormente se da a conocer -por segunda ocasión- la muerte de Nazario Moreno "el Chayo", líder, fundador e ideólogo de la Familia Michoacana y de los Templarios; a este le siguió Enrique "Kike" Plancarte Solís, otro de los principales líderes de dicha organización. A estas detenciones siguieron la de seis presuntos integrantes de los Caballeros Templarios, quienes dijeron ser escoltas de Servando Gómez Martínez, "la Tuta"15.

Asimismo, la Procuraduría General de la República detuvo a varios funcionarios por sus presuntos nexos con los Tem-

15 Información retomada de la siguiente página de internet: http://www.milenio.com/policia/Templarios-dieron-muertos-Michoacan-autodefensas_o_260374331.html plarios; el primero fue José Jesús Reyna García, ex gobernador interino de Michoacán y ex secretario de gobierno del estado y posteriormente detuvo a José Trinidad Martínez Pasalagua, ex diputado priista y líder de la Comisión Reguladora del Transporte en Michoacán. Posteriormente detuvo al alcalde de Apatzingán, Uriel Chávez, ante las denuncias de que exigía una cantidad mensual a varios regidores para apoyar a los Templarios. Posteriormente, fue detenido Octavio Aburto, alcalde de Tacámbaro por delito de peculado ${ }^{16}$.

A mediados de agosto la presidenta municipal de Huetamo, Dalia Santana, es detenida, acusada de homicidio, extorsión y acciones ligadas al crimen organizado. Antes de esta última detención, se publicó un audio y un vídeo que muestra una reunión entre Rodrigo Vallejo (hijo de Fausto Vallejo) y Servando Gómez Martínez "la Tuta"17.

De esta purga no se libraron los principales líderes de las autodefensas, el primero fue Hipólito Mora, a quien se le dictó auto de formal prisión, pero un mes después fue liberado luego de que un tribunal determinó que no hubo suficientes pruebas para procesarlo por el homicidio de dos integrantes de las autodefensas ${ }^{18}$. Un

16 Información retomada de la siguiente página de internet: http://www.excelsior.com.mx/nacio$\mathrm{nal} / 2015 / 04 / 04 / 1017133$

17 Información retomada de la siguiente página de internet: http://www.excelsior.com.mx/nacional/2015/04/04/1017133

18 Información retomada de la siguiente página de internet: http://www.excelsior.com.mx/nacional/2014/03/11/948191 
par de meses después, elementos de la policía federal y del ejército detuvieron a José Manuel Mireles, junto con 82 personas, los cargos fueron por la portación de armamento de uso exclusivo del Ejército y posesión de drogas. Una semana después, un juez federal le dictó auto de formal prisión y fue recluido en el penal federal de máxima seguridad de Hermosillo, Sonora ${ }^{19}$, donde permaneció tres años, pues fue liberado el 11 de mayo de 2017.

Los esfuerzos por desarticular a los grupos de autodefensas siguieron hasta el mes de agosto de 2014 y finalmente el 19 de agosto el Comisionado Federal de Seguridad para Michoacán, Alfredo Castillo, presentó de manera oficial la creación de la Fuerza Ciudadana para Michoacán, con esta nueva corporación dijo que se otorgaría una identidad y un proyecto de vida a sus miembros, por tanto ofreció mejores sueldos y beneficios para sus familias, como becas y seguro médico. Esta corporación sustituía en funciones a la Policía Estatal Preventiva, e inició acciones en la capital de Michoacán, para después extenderse a todo el estado ${ }^{20}$.

Sin embargo, siempre se dijo que los integrantes de ambas corporaciones no tenían un historial limpio. Por ejemplo, a Luis Antonio González, "el Americano", mando del cuerpo policiaco Fuerza Rural

19 Información retomada de la siguiente página de internet: https://aristeguinoticias.com/2706/ mexico/detienen-al-dr-jose-manuel-mireles-enmichoacan/

20 Información retomada de la siguiente página de internet: http://www.milenio.com/policia/Fuerza Ciudadana _ en _ Michoacan-Policias _ Ruralespolicia_de _elite _ ${ }_{-}$356364526.html de Michoacán, que formó parte de las autodefensas, siempre se le acusó de tener relación con Servando Gómez "la Tuta" y de estar vinculado con actividades relacionadas con el narcotráfico ${ }^{21}$.

Como se puede observar, fueron notables los logros de la intervención federal, en tan poco tiempo. Sin embargo, la violencia en sí misma no había disminuido; según reportes del Sistema Nacional de Seguridad Pública, en el primer trimestre de 2014 los homicidios dolosos se incrementaron en un $55 \%$ respecto al mismo periodo del año anterior. Esto se debe, como dice Rivera (2014), a los constantes enfrentamientos entre las fuerzas federales o las autodefensas con los criminales, o bien por el efecto cucaracha, es decir, que los grupos delictivos se empezaron a desplazar hacia otras ciudades, entre otras a Morelia, lugares en donde aumentó el número de delitos.

Durante más de un año proliferaron las autodefensas, gracias a la legitimidad, solidaridad y apoyo que fueron logrando por parte de la población, lo que les permitió avanzar por el territorio que dominaban los Caballeros Templarios, pero al llegar el Comisionado su legitimidad empieza a disminuir, impactando en su capacidad para sostener esa acción colectiva, demostrando con esto que el hecho de que los individuos compartan intereses en común no es suficiente, ya que estos grupos no lograron una identidad colec-

21 Información retomada de la siguiente página de internet: http://www.milenio.com/policia/Fuerza Ciudadana _ en _ Michoacan-Policias _ Ruralespolicia _de_elite _ ${ }_{-}$_356364526.htm 
tiva sólida para fortalecer su naturaleza de movimiento social. Esta debilidad fue utilizada por el gobierno, que al ver amenazada su tarea de ser el proveedor de la seguridad generó una estrategia para terminar con estos grupos, los cuales finalmente desaparecieron oficialmente el 10 de mayo de 2014, y por orden del gobierno federal se transformaron en fuerzas rurales a cargo de la Secretaria de Seguridad Pública estatal.

\section{CONCLUSIONES}

El surgimiento y avance de los grupos de autodefensa en Michoacán durante 2014 provocó distintas reacciones, tanto en el ámbito gubernamental, y en el académico como en el mediático. Por ello, surgieron notas, investigaciones y documentales ${ }^{22}$ interesados en dar a conocer la naturaleza de estos grupos, su implicación en la vida política y su papel en la reestructuración de las dinámicas de socialización.

Retomando lo que plantea Garretón (2002), los grupos de autodefensas están marcados por las nuevas formas de acción colectiva en América Latina, esto es, la visión crítica del Estado y la política que emana desde la sociedad civil que se plantea reforzar los principios de la ciudadanía, la participación, el empoderamiento de la ciudadanía y el capital social, ante la pérdida de legitimidad del Estado y de la democracia representativa. Como se señala en el texto, Garretón (2002) afirma que la acción colectiva en contextos

$22 \quad$ Al respecto, en julio de 2015 se empezó a transmitir el documental "Tierra de cárteles", en el cual se narra la historia de las autodefensas en Michoacán. autoritarios se funda en dos razones: la autodefensa y la sobrevivencia. En el caso de Michoacán la acción colectiva de las autodefensas se presenta como una lucha basada en la capacidad de realizar acciones de legitimación social con el objetivo de generar cambios en el universo simbólico, pero también de beneficio colectivo.

Siguiendo este planteamiento, las autodefensas son un tipo de acción colectiva con riesgo, pues hoy en día México cuenta con todas las variables de todo régimen autoritario, social, política y culturalmente represivo, en donde la inmensa mayoría de los ciudadanos se sienten agraviados, molestos y desearían generar acciones de protesta. Pero la triste realidad nos dice que si se movilizan solo algunas personas sufrirán la represión del sistema, como finalmente terminó siendo. Entonces para el éxito de cualquier acción colectiva es necesario superar un determinado número de personas en acción, ya que de esta forma es posible que el régimen no los reprima con la misma dureza y ante esta crisis se produzca un cambio en el poder. No obstante, el resultado fue la desarticulación del movimiento, a partir de la cooptación de algunos líderes -incentivos selectivos- y la represión de otros-amenazas cumplidas-.

La idea de movimiento social se desplaza en dos sentidos: cuando se presenta como respuesta a determinado momento coyuntural, situación o problema, y como la encarnación del sentido de la historia y el cambio social. En el caso de análisis, el movimiento de las autodefensas surge con la intención de generar un cambio 
social, pero al cuestionar la capacidad gubernamental para atender la demanda de protección y seguridad por parte de la población asolada por el crimen organizado, se termina en conflicto con el portador de la soberanía.

En este sentido, todo parece indicar que los distintos grupos territoriales y regionales se estaban disputando el entramado institucional; en este caso la querella inicia entre la delincuencia organizada -ya sea Familia Michoacana o Caballeros Templarios-y las autodefensas, y posteriormente es entre las autodefensas y la autoridad, a través de Alfredo Castillo en calidad de Comisionado para la Seguridad y el Desarrollo Integral de Michoacán; por tanto, la disputa termina siendo por del monopolio de la fuerza y la seguridad, y estas tareas legalmente le corresponden al Estado.

Sin embargo, ejercicios de participación ciudadana y de acción colectiva vinculados al derecho de incidir en la toma de decisiones en beneficio de una comunidad quedan relegados a simples actos ilegales. Por tanto, actores políticos como algunos medios de comunicación terminaron por reducir la complejidad del asunto a una cuestión de estar fuera o dentro de la ley, es decir, se centraban en señalar que carecían de un soporte normativo que les dieran legalidad, por lo que sus acciones, desde esta perspectiva, se ubicaban fuera del marco del Estado de derecho. Por tanto, el derecho a tomar la voz por parte de estos actores colectivos (las autodefensas) siempre fue limitado y proporcionalmente menor respecto a otras voces (como el Comisionado), y siempre fueron el blanco constante de ataques.

Al finalizar su comisión Alfredo Castillo hizo un balance sobre las acciones coordinadas entre el gobierno de la república y el del estado y los objetivos conseguidos en materia de seguridad. Reportó el abatimiento y detención de los principales líderes del crimen organizado, la desarticulación de las principales bandas de delincuentes dedicadas al secuestro y expuso los avances obtenidos para la consolidación de un mando unificado policial. Además, se ufanó de que la disminución en todos los indicadores de inseguridad mostraba que la situación de la entidad era muy diferente a la de meses atrás.

La realidad es que durante más de un año proliferaron las autodefensas y avanzaron por el territorio que dominaban los Caballeros Templarios, pero finalmente fueron disueltas por el gobierno federal y en esta "institucionalización" cavaron su propia tumba, pues como actores de la sociedad civil necesitaban de la protección de un orden legal institucionalizado para preservar su autonomía y libertad de acción, pero lo que recibieron fue lo contrario; pero lo peor fue que el problema de la violencia en Michoacán no se resolvió y formalmente quedaron disueltas en febrero de 2016.

\section{REFERENCIAS}

Animal Político (27 de enero de 2014). Las autodefensas serán institucionales: Conoce los 8 puntos que acordaron con el gobierno. Animal político. Recuperado de 
https://www.animalpolitico.com/2014/01/ las-autodefensas-seran-legales-conoce-los8-puntos-que-acordaron-con-el-gobierno/

Aristegui Noticias (27 de junio de 2014). Detienen al Dr José Manuel Mireles y 82 autodefensas en Michoacán (27 de junio, 2014). Aristegui Noticias. Recuperado de https://aristeguinoticias.com/2706/mexico/detienen-al-dr-josemanuel-mireles-en-michoacan/

Arriagada, I. y Godoy, L. (2000). Prevenir o reprimir: falso dilema de la seguridad ciudadana. Revista Cepal, (70), 107-131.

Badillo, Jesús (11 de marzo, 2014). Templarios que dieron por muertos. Milenio. Recuperado de http://www.milenio.com/policia/ Templarios-dieron-muertos-Michoacanautodefensas_o_ 260374331.html

Basave, A. (2010). Mexicanidad y esquizofrenia. Los dos rostros del mexicano. México D. F., México: Océano.

Beltrán, P. (19 de mayo de 2013). Caminos de Michoacán: los ejércitos irregulares del crimen organizado. Excélsior. Recuperado de http://www.excelsior.com.mx/pascal-beltrandel-rio/2013/05/19/899876

Carrasco, J. y Castellanos, F. (2012). Michoacán bárbaro. Revista Proceso (1837), 9-13.

Carrillo, F. (2007). Seguridad ciudadana en América Latina: un bien público cada vez más escaso. Pensamiento Iberoamericano, (0), 181-198.

Cohen, J. L. y Arato, A. (2001). Sociedad civil y teoría política. México: Fondo de Cultura Económica.

Diamond, L. (1997). Repensar la sociedad civil. Metapolítica, 1(2), 185-198.

Escalante, F. (2009). ¿Puede México ser Colombia? Violencia, narcotráfico y Estado. Nueva Sociedad, (220), 84-96.

Fuentes, A. (2014). Autodefensa y justicia en los márgenes del Estado. Clivajes Revista de Ciencias Sociales, (2), 51-65.
García, M. (4 de abril de 2015). En Michoacán van 225 exfuncionarios detenidos ligados al narco. Excelsior. Recuperado de http:// www.excelsior.com.mx/nacional/2015/04/04/ $\underline{1017133}$

Garretón, M. (2002). La transformación de la acción colectiva en América Latina. Revista Cepal, (76), 7-24.

García, M. (12 de marzo de 2014). Hipólito Mora es detenido en Michoacán; lo acusan de homicidio. Excelsior. Recuperado de http://www.excelsior.com.mx/nacional/2014/03/11/948191

La Redacción (30 de julio de 2013). Ligan a gobernador interino de Michoacán con los Templarios. Revista Proceso. Recuperado de https://www.proceso.com.mx/348801/ ligan-a-gobernador-interino-de-michoacancon-los-templarios

Maldonado, S. (2012). Drogas, violencia y militarización en el México rural: el caso de Michoacán. Revista Mexicana de Sociología, 74(1), 5-39.

Maldonado, S. (2013). Negociando la violencia, enfrentando el crimen. La construcción del orden bajo el narcotráfico. En N. Arteaga (Coord.), Violencia en México. Actores, procesos y discursos (pp. 97-126). Madrid: Catarata.

Milenio Digital (11 de marzo, 2014). Va Fuerza Ciudadana por función de policía municipal. Milenio. Recuperado de http://www. milenio.com/policia/Fuerza _ Ciudadana _en _ Michoacan-Policias _ Ruralespolicia _de _ elite _ 0 _ $356364526 . h \mathrm{tml}$

Nateras, M. (2012). Construcción de la ciudadanía y participación de los jóvenes: de la Universidad Autónoma del Estado de México. México D.F., México: UAEM-Miguel Ángel Porrúa.

Nateras, M. (2017). Autodefensas en México: fenómeno mediático y reacción social. En R. Martínez (Ed.), Comunicación política en seguridad y defensa. España y América Latina (pp. 195-212). Barcelona: Centre for Iternational Affairs (CIDOB). 
Olmos, J. (2014). Las autodefensas, divididas y cooptadas. Revista Proceso, (1959), 10-17.

Paramio, L. (2005). Teorías de la decisión racional y de la acción colectiva. Sociológica, 19 (57), 13-34.

Ravelo, R. (2011). El narco en México. Historia e historias de una guerra. México: Grijalbo.

Retamozo, M. (2009). Orden social, subjetividad y acción colectiva. Notas para el estudio de los movimientos sociales. Athenea Digital. Revista de Pensamiento e Investigación Social, (16), 95-123.
Rivera, J. (2014) Crimen organizado y autodefensas en México: el caso de Michoacán, Bogotá, Colombia: Friedrich-Ebert-Stiftung (FES).

Sánchez, J. (7 de agosto de 2013). Familia michoacana y caballeros templarios. Al momento noticias. Recuperado de http://www. almomento.mx/familia-michoacana-ycaballeros-templarios-2/

Valdivia, J. (2014). Autodefensas de Michoacán, en la encrucijada en Revista Análisis Plural, primer semestre de 2014. (pp. 183-197). Tlaquepaque, Jalisco: Iteso. 